Article

\title{
Bonus Point System for Refuse Classification and Sustainable Development: A Study in China
}

\author{
Shijie Guo ${ }^{1}$, Guomin Ding ${ }^{1, *}$, Qian Zhao ${ }^{2}$ and Meini Jiang ${ }^{1}$ \\ 1 School of Law, Fuzhou University, Fuzhou 350116, China; n161920017@fzu.edu.cn (S.G.); \\ n171927020@fzu.edu.cn (M.J.) \\ 2 School of Law, Southwest University, Chongqing 400716, China; honeywindy@swu.edu.cn \\ * Correspondence: dingguomin@fzu.edu.cn; Tel.: +86-159-595-85859
}

Received: 2 September 2017; Accepted: 28 September 2017; Published: 30 September 2017

\begin{abstract}
The rapid growth of household waste not only endangers the environment and people's health, but also limits social and economic development. The effective sorting and recycling of garbage can control this problem. Adopting a semi-quantitative case study method, our researchers investigated the effect of a bonus point system for refuse classification that improves the accuracy of refuse classification and the residents' environment awareness. In the system, residents will receive some gifts after sorting the garbage correctly. We also investigated the attitudes of residents and companies towards this novel system. Our researchers employed various methods to analyze garbage-sorting data, questionnaires completed by residents, and interview records. The results show that use of a bonus point system affects the management of domestic waste by improving the accuracy and enhancing the awareness of garbage sorting. Overall, residents support the system and benefit from it, which increases participation and consciousness of environmental protection. However, continuous publicity and coordination of various policies are required to promote the wide-range implementation and sustainable development of this system.
\end{abstract}

Keywords: refuse classification system; environment law; sustainable development; bonus point system; case study

\section{Introduction}

\subsection{Cities Besieged by Waste and Its Solution}

According to statistics from the ministry of environmental protection, 256 medium or big cities of China generate nearly 180 million tons of garbage every year. The current accumulation of garbage in the country covers an area of about 800,000 acres, and space is limited [1]. At the current rate of growth, China's municipal solid waste production will reach 4.09 million tons by 2030 [2]. While the potential environmental harm of garbage is less than that of wastewater and gas, harm may nonetheless be long-lasting on both human health and the environment [3]. The rapid growth of municipal solid waste not only increases the pressure on the prevention and control of pollution, but also incurs public costs and environmental management [4]. Landfill and incineration currently make up $98 \%$ of China's municipal solid waste treatment [5]. The use of landfills results in the release of large amounts of $\mathrm{CH}_{4}$ and $\mathrm{N}_{2} \mathrm{O}$ [6], and smoke, fly ash, and slag [7].

\subsection{Some Measures That Promote Sorting in Different Countries}

Some developed countries have made efforts to reduce the amount of garbage, recycle resources, limit the use of valuable land resources, and reduce the government's financial burden to deal with pollution [8]. Garbage sorting, in which material is effectively separated into material that can be recycled versus trash destined for disposal, is an important component of reducing the amount of 
garbage. Some countries link this sorting to punitive measures. For example, in Japan, there is a special "calendar" from the government that designates specific days for the disposal of specific kinds of garbage. Violation of these regulations will result in fines [9]. A study from Daniel reported that the ecological awareness of residents is essential for effective refuse classification [10]. From 1989 to 2004, the rate of rubbish growth in Japan began to decrease [11]. According to the report from the Contemporary Social Vision (2014) in Japan, these changes resulted in 7 million tons less waste, with a cost savings of 7.6 billion dollars. The city of Toronto implemented a regulation eliminating collection of excessive garbage, forcing citizens to directly transport any excess garbage to a waste center or face a fine of $\$ 90$ (CAD) [12]. In Singapore, people who violate the refuse classification law can be fined or jailed [13], and there are efforts to increase citizens' awareness of the need for garbage sorting [14]. These two measures contribute to Singapore being known as the "Garden City."

Market incentives to encourage household waste recycling can effectively promote refuse classification and decrease the overall amounts of garbage [15]. In the 1990s, with the slogan of "less generation, more recycling and reduce waste for disposal" Germany conducted source segregation, educated citizens, and promoted the refuse sorting principle, which led to it becoming the best country for refuse classification among the European Union (EU) members [16]. According to data from OECD in 2013, the recycling rate in Germany reached 65\%. The U.S. increases the recycling rate via providing subsidies to garbage incineration plants [17]. Korea increased its recycling rate by rewarding people who found garbage not appropriately tagged with address and name information, paying for brochures on garbage sorting and for environmental-friendly bags, and encouraging citizens to return shopping bags for money [18]. By 2010, the recycling rate of waste in Korea reached between 60 and $70 \%$, far above the average level of developed countries [19].

\subsection{China's Refuse Classification System}

China has performed garbage collection and recycling operations for over ten years with less than satisfactory results [20]. Some garbage is only classified into two types: dry and wet. What is worse, an amount of domestic garbage is not sorted before being thrown away, and toxic and harmful substances may be present in waste materials [21]. Tracing it to its cause, most old refuse classification models were in the form of top-down administration models. Citizens were required to carry out the rules directly and as instructed, which ignored their stake in the process. Therefore, a new type of waste management model is urgently needed.

The management of public affairs requires a balanced collaboration and interaction between the government and citizens. A bonus point system for refuse classification could inspire citizens' enthusiasm for participation, and improve the current confusing situation of garbage management. This study attempts to find out if this system would work effectively in China to improve the accuracy of garbage sorting and increase environment awareness.

\section{Materials and Methods}

\subsection{System Design}

A bonus point system for refuse classification is an incentive system. Cities such as Beijing, Shanghai, Hangzhou, and Xiamen have employed these systems. The characteristics of the system are described below (Figures 1 and 2). 


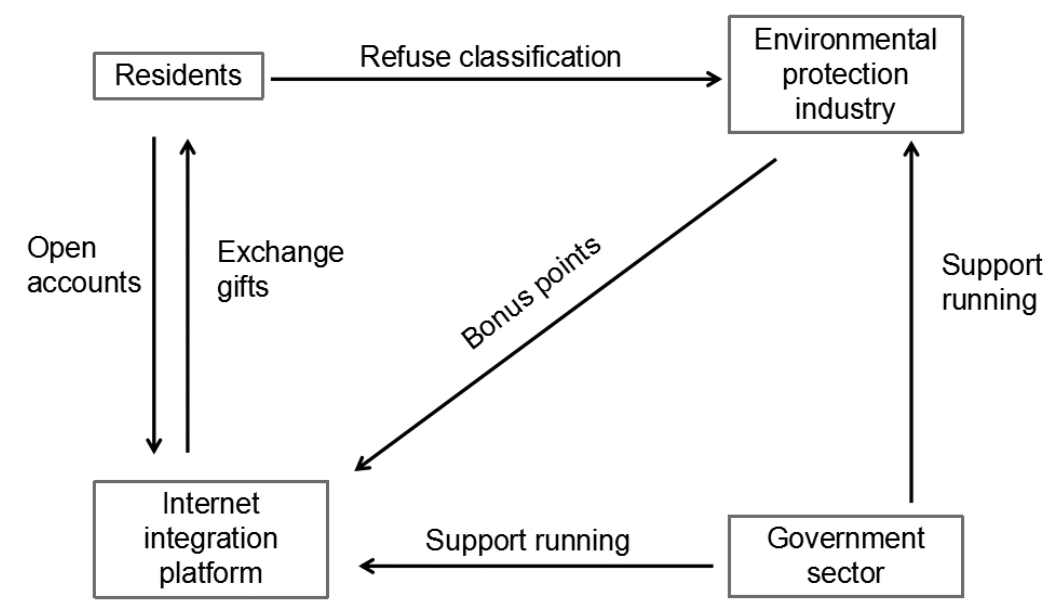

Figure 1. Bonus point system for refuse classification.

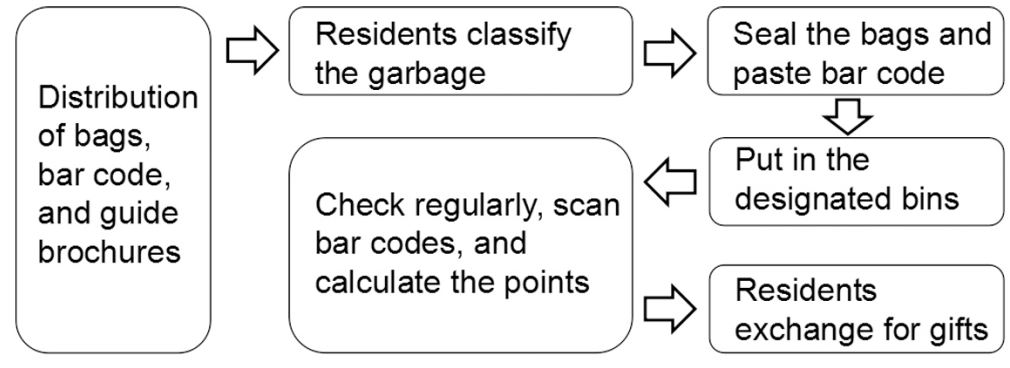

Figure 2. Process of refuse classification.

\subsubsection{Operation and Participation}

This system is currently being tried in some parts of Beijing, Shanghai, Chengdu, Hangzhou, and Xiamen, which represent the most developed cities in China. The intelligent garbage rooms of the system allow garbage identification, weighing, and bar code scanning, which are often placed near the gate of the quarter (In China, people often live in apartments. Usually, a quarter is made up of around 300 apartments, with 1000 residents). For some big quarters, more than one intelligent garbage room will be used to minimize the distance garbage will need to be carried. Residents will be informed of the benefits of garbage sorting and some of the sorted garbage will be reused. The residents will receive different-colored bags, bar codes, and guide brochures. In this system, the residents must sort the garbage into seven classes (Table 1). As not every class of garbage on the list will be produced each day, just another two or three bins are needed for sorting in most families. Common garbage rooms are also available in the pilot quarters for the garbage that is not on the list and is unsorted. All the garbage will be collected by the Municipal Environmental Sanitation Department.

\subsubsection{Operating Mechanism of Bonus Points}

An internet integration platform is used to keep track of bonus points and exchange the points for gifts. Before using the intelligent garbage room, residents must create an account on the internet integration platform. Residents take their sorted garbage to the intelligent garbage room, and the machine in the intelligent garbage room will identify the type of garbage and its weight. Residents will receive bonus points (Table 1). By scanning the code, residents can credit their account. Finally, residents can exchange points for gifts through the platform (Figure 2). When using the platform, information about refuse classification is provided. The value of 1000 bonus points is equivalent to RMB 5 yuan, which can be used on the internet integration platform. In addition, residents can also 
use bonus points in designated supermarkets. There are also monthly, seasonal, and annual awards for people who earn the most bonus points.

Table 1. Bonus points of garbage classification.

\begin{tabular}{|c|c|c|c|c|}
\hline Class & Type & Name & Unit & Bonus Points \\
\hline \multirow{4}{*}{ Solid wastes } & \multirow[t]{2}{*}{ Colored glass } & Wine bottle & kilogram (kg.) & \multirow{4}{*}{25} \\
\hline & & Colored glassware & kilogram (kg.) & \\
\hline & Colorless glass & Glass bottle, etc. & kilogram (kg.) & \\
\hline & Armored glass & Auto glass, etc. & kilogram (kg.) & \\
\hline \multirow[t]{2}{*}{ Hazardous wastes (Battery) } & Rechargeable battery & $\begin{array}{l}\text { Nickel hydrogen, nickel chromium, } \\
\text { lithium ion }\end{array}$ & kilogram (kg.) & \multirow[t]{2}{*}{1650} \\
\hline & Common dry cell & Alkaline and other not rechargeable & kilogram (kg.) & \\
\hline Hazardous wastes (E-waste) & Other digital products & $\begin{array}{l}\text { MP3, MP4, induction cooker, rice } \\
\text { cooker, radio, etc. }\end{array}$ & piece & 1350 \\
\hline \multirow{4}{*}{$\begin{array}{l}\text { Solid waste (plastics, } \\
\text { metal products) }\end{array}$} & Plastic bottle & Coke bottle, mineral water bottle & piece & 10 \\
\hline & & Other plastic products & kilogram (kg.) & 300 \\
\hline & cans & Aluminum cans, iron cans & piece & 15 \\
\hline & & Other metal products & kilogram (kg.) & 270 \\
\hline Kitchen waste & & $\begin{array}{l}\text { Leftovers, Leaves Roots and rotten } \\
\text { fruit peel, rotten leaves, etc. }\end{array}$ & kilogram (kg.) & 10 \\
\hline Solid waste (paper, cloth) & & Paper products, clothing products & kilogram (kg.) & 80 \\
\hline
\end{tabular}

\subsubsection{Sustainable Development of the System}

After being segregated, the waste is delivered to a compression station where the waste is filtered, decontaminated, deodorized and compressed before finally being sold to some factories for recycling. The money earned will be used to support the running of the internet integration platform (Figure 1). Through employing the refuse classification system, the government and the environment protection industry greatly saves money on waste disposal. The money saved can be used to establish more intelligent garbage rooms and maintain the internet integration platform. As a social public welfare undertaking, the government should fund hardware construction and daily maintenance, because the intelligent garbage room may have a high cost. Continued education efforts are also needed for the sustainable development of this system.

\subsection{Research Methods}

A semi-quantitative analysis method was used to collect and analyze the data [22]. Portions of Beijing, Shanghai, Hangzhou, Xiamen, and Chengdu (with the pilot bonus point system) were chosen, covering more than 3000 families and a total of over ten thousand residents. This research used the field observation method, questionnaire, and direct interview to collect data.

\subsubsection{Accuracy of Refuse Classification}

The five pilot quarters picked for this study were equipped with intelligent garbage rooms. Before carrying out this research, the researchers had informed the residents and obtained the permission from the owner committee. A month-long educational campaign was used. To assess refuse classification, the research group together with the local Environmental Health Department inspected bags in pilot quarters by opening them. (In order to avoid infringement of personal privacy 
and some other issues, the opening inspection was done after gathering bags together in a non-public area.) If there was one piece (for solid waste and hazardous waste) or three pieces (for kitchen waste) of garbage that failed to meet the standard, that bag was disqualified. The research group appointed two inspectors to inspect over 50 bags of sorted garbage each day to assess the accuracy of refuse classification. Each disqualified bag was photographed and recorded. Every three days of the first pilot month, this data was collected and summarized by the research group. During the following five pilot quarters, the research group opened and checked garbage bags on the first three days of each month (Figure 3). This allowed them to monitor the implementation of the bonus point system over a longer duration.

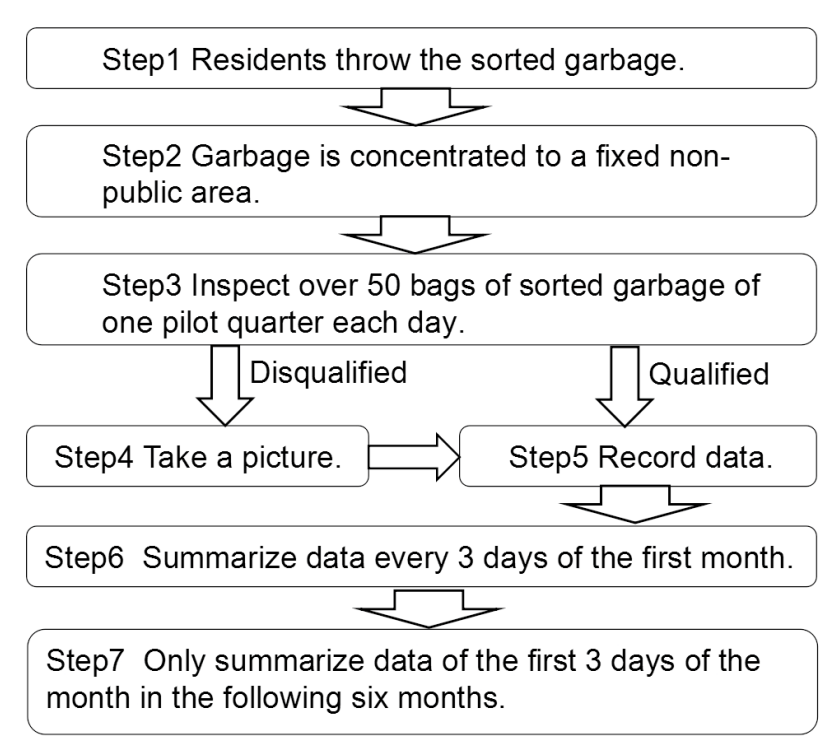

Figure 3. Accuracy assessment.

\subsubsection{Environmental Awareness}

Environmental awareness is knowledge about the environment, environmental problems, and environmental responsibility [23]. After three months' pilot of the bonus point system, the researcher selected 100 residents from the five pilot quarters ( 20 for each quarter) as the first group of objects (Group 1). Relatively, the researcher selected 1000 residents from quarters that have similar scale, residents' cognition level, and consistent consumption ability in Beijing, Shanghai, Hangzhou, Xiamen, and Chengdu (five quarters for each city and forty people for each quarter) as the second group of objects (Group 2). Once unqualified questionnaires were detected, new ones would be selected as objects. The researcher distributed questionnaires to these two groups and compared the results.

There is no universal indicator system for environment awareness [24]. A questionnaire was used as a measurement indicator system for refuse classification knowledge to measure the level of environment awareness. The questionnaire included two sections. The first section is multiple choice with 20 items in total and each item having only one correct answer. There were ten questions about refuse classification, five questions about environmental problems, and five questions about the environment (including environmental law and environmental sciences) (Table 2). The researcher judged the accuracy of the answers from the two groups and calculated each group's average grade to assess the level of environmental knowledge. 
Table 2. Questionnaire of cognition on environment situation and environment knowledge.

\begin{tabular}{cc}
\hline Questions & Number of Items \\
\hline Refuse classification knowledge & 10 points $/$ item $\times 10$ \\
Cognition on environment situation & 10 points $/$ item $\times 5$ \\
Environment knowledge & 10 points $/$ item $\times 5$ \\
\hline
\end{tabular}

The second section includes essay questions to measure residents' environmental responsibility. Five questions were designed (four for environment protection awareness and one for willingness of environmental contribution). These questions use a flexible points system, with 5 points for each question (Table 3). Residents were asked to answer these questions independently. The researcher calculated the average grade for each group to assess the level of environmental responsibility.

Table 3. Questionnaire of environmental responsibility.

\begin{tabular}{|c|c|c|}
\hline & Questions & Rating Standards \\
\hline \multirow{2}{*}{$\begin{array}{l}\text { Environment protection } \\
\text { awareness (scores accumulated) }\end{array}$} & $\begin{array}{l}\text { 1. It is hard for people like me to do something for the environment. } \\
\text { 2. There are more important things to do than environmental protection in life. } \\
\text { 3. Unless everyone makes an effort, my environment protection efforts will } \\
\text { be pointless. }\end{array}$ & $\begin{array}{c}\text { Strongly disagree }=5 \\
\text { Disagree }=4 \\
\text { Don't care }=3 \\
\text { Agree }=2 \\
\text { Fully agree }=1\end{array}$ \\
\hline & $\begin{array}{l}\text { 1. Even if it will take more money and time, I will do things that are beneficial } \\
\text { to the environment. }\end{array}$ & $\begin{array}{c}\text { Strongly disagree }=1 \\
\text { Disagree }=2 \\
\text { Don't care }=3 \\
\text { Agree }=4 \\
\text { Fully agree }=5\end{array}$ \\
\hline $\begin{array}{l}\text { Willingness to contribute to } \\
\text { the environment }\end{array}$ & $\begin{array}{l}\text { To protect the environment, to what extent would you be willing to lower your } \\
\text { living standard. }\end{array}$ & $\begin{array}{c}\text { Extremely willing }=5 \\
\text { Willing }=4 \\
\text { Just so so }=3 \\
\text { Unwilling }=2 \\
\text { Strongly unwilling }=1\end{array}$ \\
\hline
\end{tabular}

\subsubsection{Residents' and Internet Integration Platform Companies' Cognition}

The researcher conducted an in-depth interview of five residents from the five pilot quarters and three staff-members from the company that runs the internet integration platform. Using a descriptive analysis method, residents' and internet integration platform companies' cognition about this system were clearly reflected.

The following graph concludes the ways in which data is collected and analyzed (Table 4):

Table 4. Summary of data collection and analysis.

\begin{tabular}{ccc}
\hline Research Question & Data Sources & Methods of Analysis \\
\hline The accuracy of refuse classification & Field observation & Comparative analysis \\
\hline Residents' environment awareness & Group questionnaire survey & Comparative analysis \\
\hline $\begin{array}{c}\text { Residents' and internet integration platform } \\
\text { companies' cognition on this system }\end{array}$ & Interview & Content analysis \\
\hline
\end{tabular}

\section{Results}

\subsection{The Accuracy of Refuse Classification}

The horizontal axis represents days, and the vertical axis is accuracy. Before the implementation of the bonus point system, pilot quarters selected in Xiamen and Chengdu had no tradition of refuse classification. During the data collection work in Hangzhou, the research work was suspended for six days because of extraordinary rainstorms. From the graph (Figure 4), conclusions can be drawn as follows: (1) before the pilot test of the system, some people with an ordinary refuse classification system 
consciously sorted their refuse before throwing it out but with a low accuracy rate of around $32 \%$; (2) in the first pilot month of the bonus point system, the accuracy rate of refuse classification increased and was maintained at around $70 \%$ after the first month. Therefore, the bonus point system for refuse classification improved the accuracy rate of refuse classification.

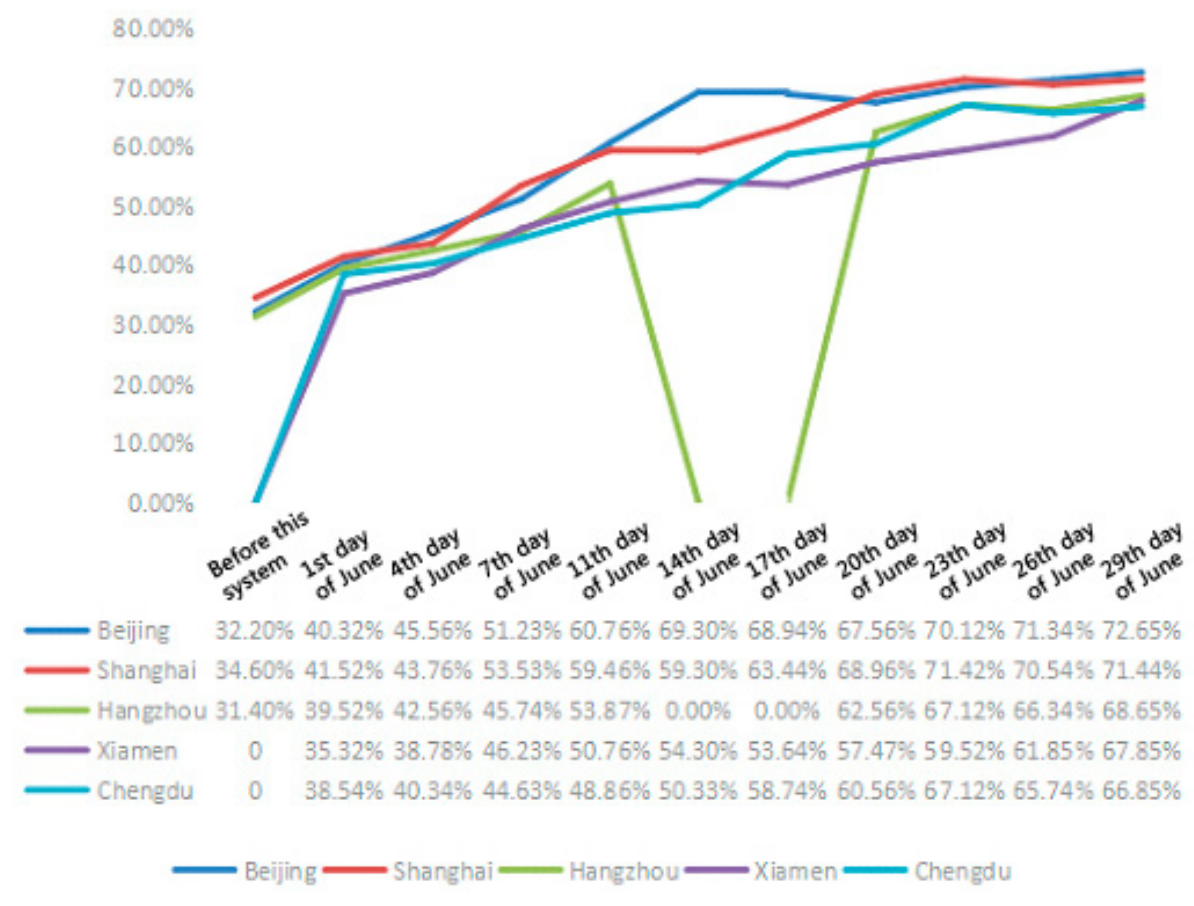

Figure 4. Accuracy of refuse classification in the first pilot month (June).

In the graph (Figure 5), the horizontal axis represents the month, and the vertical axis is accuracy. Influenced by the Hangzhou G20 summit (The G20 is an international forum for the governments and central bank governors from 20 major economies. Hangzhou G20 summit was convened on 4 and 5 September 2016. The government in Hangzhou established days off from 1 to 7 September), many residents in Hangzhou chose to go on a tour. During the research in September, Hangzhou appeared to be an "empty city" which in turn affected the involvement rate and accuracy rate of this research. From the above graphs, conclusions can be drawn as follows: (1) after implementing the bonus point system, the accuracy rate of residents' refuse classification was much higher than before, which means that the system has some practicability; (2) residents' awareness of refuse classification is casual to some extent and this system could not maintain a high involvement rate and accuracy rate. With the passing of time, the success decreased. Ongoing publicity and coordination of various policies may be needed; (3) residents' awareness of refuse classification might be influenced by a sense of group honor brought by some important events, such as the Olympics and a G20 summit. In the graph, it can be seen that the accuracy rate in Hangzhou during the later investigation phrase was higher than those in other cities, possibly due to the influence of the G20 summit. 


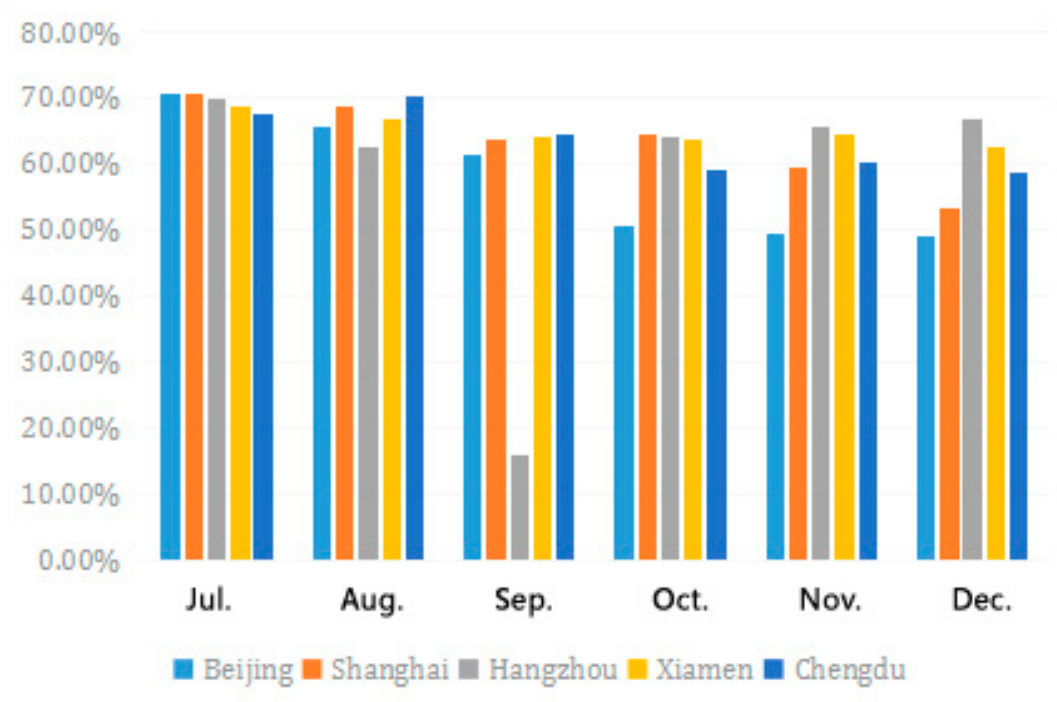

Figure 5. Bar graph for the accuracy rate of refuse classification from July to December.

\subsection{Residents' Level of Environment Awareness}

\subsubsection{Cognition about Environmental Situations and Environmental Awareness}

The average score for the 20 questions about environmental knowledge related to refuse classification is shown in Table 5.

Table 5. Questionnaire results of environmental knowledge.

\begin{tabular}{cccc}
\hline Questions & Group 1 (Points) & Group 2 (Points) & Conclusion \\
\hline Refuse classification knowledge & 51 & 22 & $>29$ \\
Cognition on environment situation & 34 & 22 & $>12$ \\
Environment knowledge & 27 & 22 & $>5$ \\
\hline
\end{tabular}

As seen from the above statistics, it is obvious that residents in group 1 had a higher accuracy of answering the questions on the questionnaire compared with group 2. To some extent, that shows that involvement in the bonus point system can effectively improve awareness of China's environmental crisis, environmental science and related laws, and the level of refuse classification knowledge. Overall, knowledge was improved.

\subsubsection{Environmental Responsibility (Sense of Justice for Environment)}

Environmental responsibility is the ideological basis of environment protection [25]. This is the fundamental guarantee of the fulfillment of sustainable development and will directly influence people's ideas of environment protection [26]. In this research, the mean values for each group's scores on questions related to environment protection responsibility are as follows (Table 6):

Table 6. Results analysis of environment responsibility.

\begin{tabular}{cccc}
\hline Questions & Group 1 (Mean Value) & Group 2 (Mean Values) & Conclusion \\
\hline Environment protection awareness (scores accumulated) & 12.18 & 9.72 & $>2.46$ \\
Willingness to contribute to the environment & 3.81 & 3.51 & $>0.3$ \\
\hline
\end{tabular}

Environment protection awareness and willingness to contribute to the environment protection function as a pivotal engine to emission reduction [27]. Higher environment protection awareness and 
willingness to contribute to environment protection lead to emissions reduction [28]. According to the results from the questionnaire, in terms of environment protection awareness, the mean of Group 1 is 2.46 higher than that of the Group 2. The willingness to lower one's living standard to protect the environment in Group 1 is also higher than that of Group 2. Through comparing and analyzing of the research results, it can be seen that objects in Group 1, who are involved in the bonus point system of refuse classification, have a stronger willingness to back the welfare of the environment, and they are more willing to implement low-carbon ideas in their work and life.

\subsection{Residents' and Internet Integration Platform Companies' Cognition}

\subsubsection{Residents' Cognition on the System}

The researcher conducted an in-depth interview of five residents involved in this research to assess their knowledge of the bonus point system of refuse classification. Residents praised the positive effects of this innovative system on the problems of China's refuse classification. Specifically, the reasons elaborated by them are as follows: firstly, as a kind of incentive system, the bonus point system encourages refuse classification and is an important part of a "refuse reduction strategy". With the implementation of the Environment Protection Law, the promotion of a socialized way of waste reduction has become a critical driving force in refuse classification; secondly, the bonus point system encourages a higher involvement rate of local residents. This helps environment protection and residents' awareness; thirdly, the intelligent management system used here does not require high cost or human resource use; fourthly, garbage itself cannot directly produce benefits but significant additional value will be created when people from all walks of life and residents are connected on-line and off-line through using big data produced by the garbage classification intelligent management system. The garbage classification intelligent process will be accelerated by using these additional values to incentivize residents to sort garbage by setting up an off-line refuse classification community platform and an on-line refuse classification management platform.

\subsubsection{Internet Integration Platform Companies' Cognition on the System}

The researcher conducted an interview with three staff-members from the internet integration platform company. The interview results show that they affirmed the positive effects that this innovative system might present to China's current refuse classification crisis. They also made suggestions on how to improve the program. They all agreed that the promotion of a bonus point system provides a great incentive to changing residents' refuse classification behavior. Besides, the introduction of Internet intelligent management mode would greatly reduce the management costs, being more convenient for residents, thus becoming a system with higher feasibility. Staff in Shanghai Public Benefit of Green Welfare Developing and Promoting Center said the following:

"In 2015, Shanghai set up the green account management and running unit and institution. In the same year in July, 'Green account internet plus' platform was officially launched. As an internet platform of the green account, it is equipped with modern scientific technology. Residents can learn refuse classification knowledge, check the points inside the green account, and give feedbacks and suggestions through channels such as official website, wechat, and APP. By the end of March 2017, after the efforts from the related departments in districts and counties and positive promotion and collaboration from social groups and the third-party companies, distribution of the single cards and set cards of green account has respectively reached 1.814332 million and 0.131730 million families. It has been in a certain scale, with the total coverage of families reached 2.415406 families and the total points of 1.27 billion points."

It takes a long time to cultivate residents' refuse classification behavior which means that the essence of the "bonus point system" lies in its sustainable development. Principal Li Zhen from Beijing Innovative Wisdom Sanitation Development co. LTD said the following: 
"Refuse classification is not originated from Beijing. Many cities have tried to do it. Efforts as quarters using recyclable refuse to offset the property fees and environment protection industries in Hangzhou entering local quarters to recycle recyclable refuse under bonus point system are not rare. However, the problem lies in that no matter who will give the rewards of refuse classification, the challenge of sustainable development cannot be avoided. Many tries failed in a short period after launched for the cost of running. In our country, the comprehensive utilization of waste industry is still at start-up stage. Therefore, compared with the developed countries, there is a huge gap in terms of the range of waste disposal and ways of disposal. Objectively, those are all obstacles for the going of sorted garbage and constrain the joint between the comprehensive utilization of waste industry and garbage collection."

\section{Discussion}

\subsection{The Rationality and Validity of the Experiment}

Though we have ignored some factors that may affect the results of the experiment, we firmly believe that this experiment testifies to the effectiveness of this system, which is practical and worth being promoted and extended. This system was mainly used in the biggest and most developed cities in China, so the people there would have been better educated, which allowed for easier promotion. Due to high costs of manpower and material, we only inspected the garbage daily for the first month and the first three days of the following six months. This may affect the accuracy of the experiment, but we conclude that this system improves the current situation of refuse management and improves public awareness of refuse classification.

\subsection{An Innovative Mode to Solve the Environmental Dilemma}

Use of a bonus point system can help to counter China's refuse classification problems. The bonus point system uses points to motivate residents to perform refuse classification and facilitate resource recycling. During the operation of this system, residents must sort the refuse correctly and then they will be rewarded with points that can be exchanged for daily goods. This allows residents to see a positive connection between their aims and the possibility of achieving them [29]. The system promotes residents' awareness and enthusiasm for refuse classification.

\subsection{Improved Environmental Knowledge}

Due to the limited popularization of refuse classification, some residents lack information about the environment and policies about refuse classification. Some districts and quarters are still outside the refuse classification system. After this study, there was improvement of public awareness of environment protection by their participation in refuse classification.

\subsection{The Need of Relative Laws and Regulations for Sustainable Development}

The segregation accuracy decreases over time, which means additional measures can be used together. Above all, ongoing garbage knowledge education efforts are required, including signs and advertising. There are few laws and regulations about domestic refuse classification in China, and more comprehensive refuse classification and resource recycling regulations are warranted. Pilot refuse classification cities often failed to achieve their aim because of problems related to the high mobility of their migrant populations. To maintain and enlarge the fruits of this research, firstly, we need laws and regulations on refuse classification in our country, which will ensure the implementation of refuse classification work and protect the present effects that have been achieved; secondly, we need to gradually set up a regurgitation-feeding institution. Garbage itself is the product of consumption, so the cost of recycling waste resources should be extracted from the process of production and consumption. By involving it in economic policy, the setting up of a regurgitation-feeding institution 
will help turn refuse management into an industry. Besides, it satisfies the concept of sustainable development and will also render the service and management of refuse classification feasible.

\section{Conclusions}

This study examined the effects of a novel environmental protection strategy, a bonus point system for refuse classification. A case study was performed for more than one year. We employed comparative and content analysis methods to analyze the data. Our main conclusions can be summarized as follows:

1. The system constructs a new mode of garbage sorting. This is an effective method of refuse reduction, recycling, and re-utilization. Our researchers used empirical data to analyze the system. Under this system, the accuracy of residents' garbage sorting was much higher, suggesting that the system has some practicability. The bonus point system is beneficial for increased public involvement and increased accuracy of garbage sorting.

2. Genuine knowledge comes from practice. There was improved environment awareness after implementing this system, with residents more willing to take on environmental protection responsibility. During the pilot period, there were regular activities on the internet platform that promoted garbage knowledge education. Residents were involved directly in garbage sorting, which effectively increased their awareness of environmental protection. However, ongoing publicity and coordination of various policies are still required.

Overall, our research provides strong evidence for the effectiveness of a bonus point system. This system promotes garbage sorting and enhances residents' awareness of refuse classification. However, the bonus point system is not an end but a method. The decline in accuracy over time suggests that ongoing garbage knowledge education, legislative improvement and some other methods are needed. Future studies should examine these areas and establish ways in which to finance these programs in urban environments.

Acknowledgments: This work was supported by the National Social Science Foundation of China (Grant No. 14AZD146) and the Southwest University Base of Ministry of Culture (Grant No. 16GGWHW013).

Author Contributions: Shijie Guo, Guomin Ding, and Qian Zhao conceived and designed the research; Meini Jiang contributed to the initial analysis of the data; and Shijie Guo and Guomin Ding wrote the paper.

Conflicts of Interest: The authors declare no conflict of interest.

\section{References}

1. Yang, H.; Xia, J.; Thompson, J.R.; Flower, R.J. Urban construction and demolition waste and landfill failure in Shenzhen, China. Waste Manag. 2017, 63, 393-396. [CrossRef] [PubMed]

2. Bie, R.; Song, X.; Ji, X.; Chen, P.; Liu, Q. Status and policy of domestic waste treatment at home and abroad. China Resour. Compr. Util. 2013, 9, 31-35. [CrossRef]

3. Vrijheid, M. Health effects of residence near hazardous waste landfill sites: A review of epidemiologic literature. Environ. Health Perspect. 2000, 108, 101. [CrossRef] [PubMed]

4. Abas, M.A.; Wee, S.T. Municipal solid waste management in Malaysia: An insight towards sustainability. Int. Conf. Hum. Habitat Environ. 2016. [CrossRef]

5. Hong, J.; Chen, Y.; Wang, M.; Ye, L.; Qi, C.; Yuan, H.; Zheng, T.; Li, X. Intensification of municipal solid waste disposal in China. Renew. Sustain. Energy Rev. 2017, 69, 168-176. [CrossRef]

6. Wang, X.; Jia, M.; Lin, X.; Xu, Y.; Ye, X.; Kao, C.M.; Chen, S. A comparison of $\mathrm{CH}_{4}, \mathrm{~N}_{2} \mathrm{O}$ and $\mathrm{CO}_{2}$ emissions from three different cover types in a municipal solid waste landfill. J. Air Waste Manag. Assoc. 2017, 67, 507-515. [CrossRef] [PubMed]

7. Margallo, M.; Taddei, M.B.M.; Hernández-Pellón, A.; Aldaco, R.; Irabien, A. Environmental sustainability assessment of the management of municipal solid waste incineration residues: A review of the current situation. Clean Technol. Environ. Policy 2015, 17, 1333-1353. [CrossRef]

8. Zhu, B.; Wang, Y.; Wang, W.; Zhao, N. Status and development trend of urban garbage resource. Appl. Energy Technol. 2015. [CrossRef] 
9. Takaoka, E.; Tanaka, Y.; Nakanishi, M. Implementation and evaluation of adaptive garbage collection. Syst. Comput. Jpn. 2015, 31, 83-90. [CrossRef]

10. Guerin, D.; Crete, J.; Mercier, J. A multilevel analysis of the determinants of recycling behavior in the European countries. Soc. Sci. Res. 2001, 30, 195-218. [CrossRef]

11. Usui, T.; Kakamu, K.; Chikasada, M. To introduce recycling or not: A panel data analysis in Japan. Resour. Conserv. Recycl. 2015, 101, 84-95. [CrossRef]

12. McDavid, J.C.; Mueller, A.E. Across-Canada analysis of the efficiency of residential recycling services. Can. Public Adm. 2008, 51. [CrossRef]

13. Tan, R.B.; Khoo, H.H. Impact assessment of waste management options in Singapore. J. Air Waste Manag. Assoc. 2006, 56. [CrossRef]

14. Zhang, D.; Tan, S.K.; Gersberg, R.M. A comparison of municipal solid waste management in Berlin and Singapore. Waste Manag. 2010, 30, 921. [CrossRef] [PubMed]

15. Reschovsky, J.D.; Stone, S.E. Market incentives to encourage household waste recycling: Paying for what you throw away. J. Policy Anal. Manag. 1994, 13, 120-139. [CrossRef]

16. Wang, J. Comparison of waste sorting in China and Germany and waste sorting method in China. Environ. Sanit. Eng. 2004. [CrossRef]

17. Bom, U.B.; Belbase, S.; Bibriven, R. Public perceptions and practices of solid waste recycling in the city of laramie in Wyoming, USA. Recycling 2017, 2. [CrossRef]

18. Yang, W.S.; Park, J.K.; Park, S.W.; Seo, Y.C. Past, present and future of waste management in Korea. J. Mater. Cycles Waste Manag. 2015, 17, 207-217. [CrossRef]

19. Lee, D.H.; Behera, S.K.; Kim, J.W.; Park, H.S. Methane production potential of leachate generated from Korean foodwaste recycling facilities: A lab-scale study. Waste Manag. 2008, 29. [CrossRef]

20. Steuer, B.; Ramusch, R.; Part, F.; Salhofer, S. Analysis of the value chain and network structure of informal waste recycling in Beijing, China. Resour. Conserv. Recycl. 2016, 117. [CrossRef]

21. Fei, F.; Qu, L.; Wen, Z.; Xue, Y.; Zhang, H. How to integrate the informal recycling system into municipal solid waste management in developing countries: Based on a China's case in Suzhou urban area. Resour. Conserv. Recycl. 2016, 110, 74-86. [CrossRef]

22. Kostoff, R.N. Assessing research impact: Semiquantitative methods. Eval. Rev. 1994, 18, 11-19. [CrossRef]

23. Shen, X. Environmental economics: Theoretical foundations, policy tools and prospect. Xiamen Univ. (Philos. Soc. Sci. Ed.) 2008, 4, 19-26. [CrossRef]

24. Wolters, M.L.; Sun, Z.; Huang, C.; Kuenzer, C. Environmental awareness and vulnerability in the Yellow River Delta: Results based on a comprehensive household survey. Ocean Coast. Manag. 2016, 120, 1-10. [CrossRef]

25. Sáez-Martínez, F.J.; Díaz-García, C.; González-Moreno, Á. Factors promoting environmental responsibility in European SMEs: The effect on performance. Sustainability 2016, 8. [CrossRef]

26. He, P.; Zhuang, Y.; Lin, Y.; Zheng, C. Environmental law clinics in collaboration with environmental NGOs in China. Sustainability 2017, 9, 337. [CrossRef]

27. Liobikien, G.; Juknys, R. The role of values, environmental risk perception, awareness of consequences, and willingness to assume responsibility for environmentally-friendly behaviour: The Lithuanian case. J. Clean. Prod. 2016, 112, 3413-3422. [CrossRef]

28. Nie, W. Environment cognition, environmental responsibility and public mitigation action. Sci. Technol. Manag. Res. 2016, 15, 252-256. [CrossRef]

29. Fellowship, M. Expectancy-value theory of achievement motivation. Contemp. Educ. Psychol. 2017, $25,68-81$. [CrossRef]

(C) 2017 by the authors. Licensee MDPI, Basel, Switzerland. This article is an open access article distributed under the terms and conditions of the Creative Commons Attribution (CC BY) license (http:/ / creativecommons.org/licenses/by/4.0/). 